\title{
Phase Doppler quantification of agricultural spray compared with traditional sampling materials
}

\author{
R.L. Roten ${ }^{1}$, S.L. Post $^{1}$, A. Werner ${ }^{1}$, M. Safa ${ }^{2}$ and A.J. Hewitt ${ }^{3}$ \\ ${ }^{1}$ Lincoln Agritech Ltd., P.O. Box 69133, Lincoln, Christchurch 7640, NZ \\ ${ }^{2}$ Lincoln University, P.O. Box 7647, Lincoln, Christchurch 7647, NZ \\ ${ }^{3}$ The University of Queensland, Gatton QLD 4343, Australia \\ Corresponding author: rory.roten@lincolnagritech.co.nz
}

\begin{abstract}
The quantification of spray mass has historically been accomplished by means of fluorescent dyes and various string and ground samplers to capture the dye-laden spray. However, these methods are typically not used in close proximity to orchard sprayers and are prone to many sources of error. The objective of this study was to assess the ability of an in-field phase Doppler (pD) interferometer to quantify spray mass against two common string samplers. Measurements were taken at $0.5 \mathrm{~m}$ increments to $4.5 \mathrm{~m}$ vertically and $1.0 \mathrm{~m}$ increments to 5.0 $\mathrm{m}$ downwind from the spray. Converted flux measurements from the strings were compared with those obtained using the $\mathrm{pD}$ interferometer. The current $\mathrm{pD}$ technology was found to be incapable of collecting equivalent flux data to that obtained from the strings. However, the $\mathrm{pD}$ equipment did provide useful data on droplet velocity and size.
\end{abstract}

Keywords spray mass; phase Doppler interferometer; flux; droplet size; velocity.

\section{INTRODUCTION}

In 2015, New Zealand horticultural export crops were worth approximately $\$ 4.3$ billon per annum, the majority of which is made from fresh fruits and processed fruit goods: apples; kiwifruit; wine; avocados; and fruit juices (Anon. 2015). Export market phytosanitary requirements and the New Zealand maritime climate together require the use of agrichemical spray programmes to kill pests and diseases. Agrichemical inputs to horticultural crops make up approximately $40 \%$ of the total NZ agrichemical use (Manktelow et al. 2005). This is due to an increase in newly introduced pests and diseases, such as Pseudomonas syringae pv. Actinidiae (Psa) and Grapholita molesta (oriental fruit moth), which negatively affect horticultural production (Vanneste et al. 2011; Lo and Walker 2016). Consequently, the intensification of agrichemical spray programmes, and agrichemical spraying, will continue to be an essential part of successful horticultural production for the foreseeable future.

The assessment of pesticide spray deposition in orchards and vineyards is complex because many factors can influence spray deposits. Firstly, horticultural canopies can range from ca. 1.3 to $>10.0 \mathrm{~m}$ in height and ca. 0.3 to $>5.0$ $\mathrm{m}$ deep (using grapevines and avocados as examples of extremes). However, similar spray delivery technologies are used across the range of horticultural crops (namely one of many axial fan airblast varieties) despite these widely diverse canopies. It is important to have an understanding of the characteristics of the crop canopy to ensure the application of spray is 
on target and efficient. Key factors are sprayer droplet sizes, turbulence and wake effects, as well as how these interact together with the weather conditions at the time of application (Fox et al. 1990; Miller et al. 2000; Salyani et al. 2007). Although agrichemicals ultimately target pest or disease organisms, the primary target of spray application is the crop canopy where the default application aim is to maximise spray retention on the target as uniformly as practical. Secondly, understanding the potential movement of these pesticide-laden droplets outside of the crop is important to minimise the risk of drift and offtarget contamination.

Historically, many types and styles of samplers have been used to measure spray deposits and coverage (Bui et al. 1998). Coverage has been observed by means of fluorescent dyes, water sensitive papers (WSPs), spray additives such as Kaolin clay (e.g. Surround ${ }^{\circledR}$ ) or Kromekote ${ }^{\circledR}$ paper with coloured dye. However, coverage does not quantitatively inform the applicator of deposition of the active ingredient in the canopy or per unit area (Roten et al. 2015a). This is especially true in orchard environments when the carrier volume can saturate the canopy as well as the samplers. Further, droplet size assessment in-field can also be subjective with quantitative assessments of the spectrum of droplets being difficult, particularly where large carrier volumes are applied which may saturate the sampler (Fox et al. 2003).

Various sampler riggings have been used for drift measurements and some have included efforts towards understanding the pattern of the spray vertically. These methods to assess spray plume patterns (patternation) in agriculture (aerial, ground and orchard sprayers) have been investigated since the late 1950s. Whitney and Roth (1985) devised a way of doing this using a string system and a relatively automated fluorimeter to assess the pattern. More recent studies, such as Balsari et al. (2005) and Salyani et al. (2007), have used engineered approaches to suspend samplers (strings or cellulose filter cloth) to assess the movement of liquid mass through orchard vegetation. However, none of these provide quick, quantitative and repeatable measurements.

Phase Doppler (pD) technology uses two crossing laser beams to create a detectable electrical signal: as droplets pass this area (probe volume), the electrical signal changes, and this change ultimately determines the size, velocity and flux of the passing droplets (Bachalo 1980; Bachalo 1984). In the late 1980s, the first fully enclosed $\mathrm{pD}$ interferometer was created to assess aircraft icing and later cloud dynamics (Rudoff et al. 1992; Chuang et al 2008). This technology remained unchanged until 2011 when Artium Technologies Inc. introduced the Demeter probe for in-field agricultural spray assessment (Hewitt et al. 2013). Since then, the TurnKey Probe (Artium Technologies Inc, Sunnyvale, CA, USA) has been introduced, which was used here. To date, no published research has occurred to test $\mathrm{pD}$ technology in outdoor, agricultural environments or in close proximity to an orchard sprayer. Initial work was conducted in laboratory and wind tunnel environments to test $\mathrm{pD}$ technology against traditional string samplers. These preliminary studies concluded that $\mathrm{pD}$ technology had developed to the point where it was ready to be taken to the field and tested (Roten et al. 2016 a, b). Therefore, the objectives of the present study were to: (1) validate mass collection of pD data against two common string types; (2) compare samplers for patternation assessment; and (3) assess spray plume characteristics, such as drop size distribution and droplet velocity, that cannot be obtained using static collectors.

\section{MATERIALS AND METHODS}

A Taral three-point linkage style axial fan orchard sprayer (Taral, Instanbul, Turkey) was used to deliver an application volume of $9.5 \mathrm{litre} / \mathrm{min}$ from the left side of the sprayer using four ceramic disc nozzles. Nozzle orientation was recorded and kept consistent for the duration of the study. To ensure consistency as best as possible, the weather was closely observed, predominately for wind direction, which varied from a North Easterly $\left(33.75-56.25^{\circ}\right)$ to West North West $\left(281.25-303.75^{\circ}\right)$. Any wind direction between 
these angles was suitable for the trial (Table 1). A wind vane on site was used as a visual reference during spray treatments. In addition, recorded data were obtained using the National Institute of Water and Atmospheric Research (NIWA) Broadfield Electronic Weather Station (\#17603) at Lincoln University, which was $350 \mathrm{~m}$ from the experimental site.

\section{String sampling}

A total of five replicates were taken for the string measurements: two full replications on 22 October 2016 and three replications on 6 December 2016. The chosen strings for testing were a 2.0 $\mathrm{mm}$ smooth nylon string (strimmer line, Stihl, Weingärten, Germany) and $1.7 \mathrm{~mm}$ natural cotton string (Birch Haberdashery, Heidelberg, Victoria, Australia). Strings were pre-cut to a length of 4.7 $\mathrm{m}$ with a targeted sampling length of $4.5 \mathrm{~m}$, using the excess material to securely attach the strings to the sampling frames. Strings were vertically suspended on a $1.5 \mathrm{~m}$ by $6.0 \mathrm{~m}$ array using scaffolding frames erected at 1, 2, 3, 4 and $5 \mathrm{~m}$ downwind of the spray in a staggered arrangement (Figure 1). The strings were attached to a $70-\mathrm{mm}$ by 1,000-mm pvc pipe. A pulley system suspended from the top of each frame was used to raise the strings to an approximate height of $4.5 \mathrm{~m}$. It is commonplace to have quasi-replicates on the same treatment in spray drift research. Therefore, 6 strings ( 3 cotton and 3 nylon) were attached to each sampling rig $100-\mathrm{mm}$ apart. The strings were attached to an additional 1,000-mm pipe, which was tied to the bottom of the scaffolding frame to stretch and secure them at ground level. The sprayer was driven at a speed of $2.3 \mathrm{~km} / \mathrm{h}$ to provide sufficient deposition on the string samplers. Tap water was mixed with approximately $2 \mathrm{~g} /$ litre of the fluorescent tracer PTSA (1,3,6,8-pyrenetetrasulfonic acid tetrasodium salt; Spectra Colors Corporation, Kearny, New Jersey, USA) and adequately agitated in the sprayer until mixed for dye recovery and quantification. After the given spray event, 15 minutes were allowed to elapse to ensure the strings were dry, then they were carefully rolled onto the bottom pipe and stored in clean plastics bags. All bagged samples were placed in a freezer within 30 minutes to avoid any potential degradation. This system allowed for quick turnaround of treatments as well as eliminating many concerns for contamination.

\section{Phase Doppler sampling}

The $\mathrm{pD}$ data of interest included the flux, velocity and key droplet size characteristics (Dv0.1, Dv0.5, and Dv0.9) and was extracted using AIMS (Artium Integrated Management Software). The $\mathrm{pD}$ system tested was the TurnKey probe (model: TK1-600; Artium Technologies, Sunnyvale, CA, USA), which is an enclosed system. It requires no positioning or alignment of laser beams, and allows for droplets ranging from 5 to $694 \mu \mathrm{m}$ in size to be measured in-field. However, due to the small sampling area of the $\mathrm{pD}\left(\mathrm{ca} .1 \mathrm{~mm}^{2}\right), \mathrm{pD}$ sampling required a longer time than string samples to obtain sufficient data for a valid measurement. Therefore, it was not feasible to have simultaneous $\mathrm{pD}$ data acquisitions with the strings nor was it possible to acquire data with a moving tractor. Consequently, $\mathrm{pD}$ treatments were undertaken on a separate day (16 February 2017), and data were acquired with the tractor/sprayer in a static position spraying only water and at the same sampling increments as the strings. A minimum of two replications

Table 1 Weather data for experimental days from the Lincoln University Broadfield weather station, accessed from NIWA's Cliflo database.

\begin{tabular}{cccccc}
\hline $\begin{array}{c}\text { Sampler } \\
\text { type }\end{array}$ & Date & $\begin{array}{c}\text { Wind Direction } \\
\left({ }^{\circ}\right)\end{array}$ & $\begin{array}{c}\text { Wind Speed } \\
(\mathrm{m} / \mathrm{s})\end{array}$ & $\begin{array}{c}\text { Temperature } \\
\left({ }^{\circ} \mathrm{C}\right)\end{array}$ & $\begin{array}{c}\text { Humidity } \\
(\%)\end{array}$ \\
\hline Strings & 22 Oct 2016 & $41.1 \pm 12.6$ & $6.2 \pm 1.1$ & $13.1 \pm 1.6$ & $63.3 \pm 6.8$ \\
Strings & 6 Dec 2016 & $298.8 \pm 15.5$ & $4.3 \pm 1.1$ & $24.8 \pm 1.8$ & $52.2 \pm 8.4$ \\
pD & 16 Feb 2017 & $47.1 \pm 13.6$ & $7.2 \pm 1.4$ & $20.2 \pm 1.1$ & $72.0 \pm 6.9$ \\
\hline
\end{tabular}



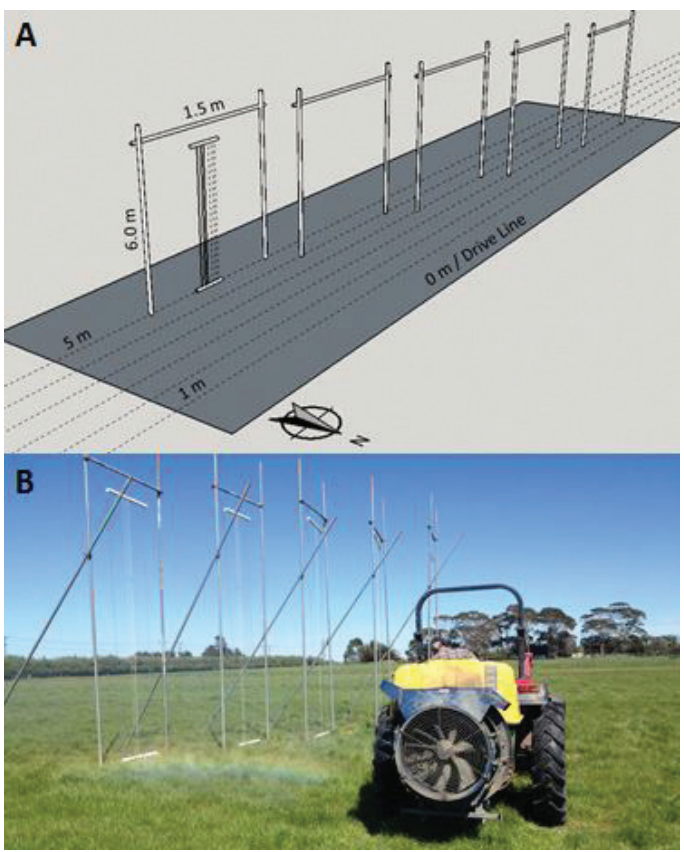

Figure 1 (A) Illustration of sampler frame design and string apparatus (5-m frame only); and (B) photograph of an experiment being conducted.

were taken, which was time dependent. It was unrealistic to obtain more than two replicates in areas of low flux whereas areas of high flux had more replication due to being less time restrictive.

\section{Analysis}

For laboratory processing, designated strings were removed from the freezer and each string individually uncoiled. Because of slight differences in string length, each string was harvested from the bottom/ground level as a $0.0 \mathrm{~m}$ point was known. From here, $0.5-\mathrm{m}$ sections were cut, individually stored in pre-labelled bags, and either returned to the freezer or underwent immediate processing. Dye extraction was accomplished by adding 24 $\mathrm{mL}$ of 90:10 water:isopropanol to the same bags in which the sample was stored. Each bag was agitated/ shaken for a few seconds to ensure that the sample was submerged in the extraction fluid, and allowed to rest for a minimum of 15 minutes. A 3-mL subsample was then taken and dye quantification performed using a fluorometer to provide a linear RFU (relative fluorescence unit) value with a 350$\mathrm{nm}$ excitation wavelength PTSA module (Turner Trilogy ${ }^{\circledR}$, Turner Designs, Sunnyvale, CA, USA). A standard, linear fit curve was then used to convert the RFU data to $g /$ litre. For this, a stock solution of $2 \mathrm{~g} /$ /itre PTSA was made using the 90:10 water:isopropanol mix and processed using increasing sample concentrations until quenching was observed. Linearity was observed up to $1.6 \mathrm{M}$ RFUs $\left(r^{2}=0.992 ; y=2.65^{\star} 10^{8} x\right)$ and samples above this value were diluted and reprocessed accordingly. Tank samples, which were taken at each string run, were also processed to obtain the true PTSA concentration of the tank. The associated data per tank concentration were then normalised to a uniform concentration of $1.74 \mathrm{~g} /$ litre.

The $\mathrm{pD}$ data processors use time as a key parameter to calculate flux but time is an independent variable to the sprayer. At any point in time that introduced interferences (e.g. wind and droplet agglomeration) restrict the plume from the collection area, the computer continues to add time that is not reflective of the actual data. These times of no data, or gaps, had to be removed before final processing. Gaps were removed by applying a correction algorithm to the data series whereby the computed flux was multiplied by the quotient of true data over total data. True data were defined as points where data were recorded versus total data included nonexistent data (time data recorded in between true data points). Up to $85 \%$ of the field data presented here was gapped. This does not indicate that $85 \%$ of the data were missing, but that the spray plume was in the sampling area of the $\mathrm{pD}$ interferometer for $\geq 15 \%$ of the time. Similarly, Dullenkopf et al. (1998) found that time-sequence data obtained in a laboratory patternation assessment using a similar $\mathrm{pD}$ device contained up to $5 \%$ gaps.

Finally, string deposition data were converted to a unit of flux $\left(\mathrm{mL} / \mathrm{s} / \mathrm{cm}^{2}\right)$ using the string recovery data to express time with a known dye output of $0.276 \mathrm{~g} / \mathrm{s}$. Here, flux is defined geometrically as the volume of liquid spray passing through the sampling area divided by that area, per unit time. These flux data, as well 
as velocity and droplet size distributions, were then separated by distance and height. Means were separated using Tukey's HSD (honest significance difference) with a $95 \%$ confidence level using $\mathrm{R}$ (version 3.2.0, $\mathrm{R}$ Foundation for Statistical Computing, Vienna, Austria).

\section{RESULTS AND DISCUSSION \\ Comparison of string and $\mathrm{pD}$ methods}

No statistical differences were observed among any string flux replicates $(\mathrm{P}=0.30$ to 0.99$)$, therefore, all replicates were kept for analysis. This result indicated that both string systems were effective in capturing a representative amount of dye in each trial. Also, there was no significant difference between deposition on cotton or nylon $(\mathrm{P}=0.19)$. However, there was a significant, 18-fold difference between deposition for cotton or nylon and that of the $\mathrm{pD}$ interferometer $(\mathrm{P}<0.05)$. This result showed that the $\mathrm{pD}$ equipment was not effective in capturing a representative amount of droplets in each trial. This ineffectiveness was due to the low sampling frequency for accurate flux measurements. Ideally 10,000 to 20,000 counts (individual droplets passing through the probe volume) are needed but $>2,000$ counts were seldom achieved here. Further, the $\mathrm{pD}$ interferometer was unable to obtain any data beyond a height of $2.5 \mathrm{~m}$ or a distance $>4.0 \mathrm{~m}$. It was, therefore, concluded that $\mathrm{pD}$ technology is not currently an appropriate replacement for string samplers.

\section{Patternation}

The flux of the spray plumes determined at different heights and various distances from the sprayer using cotton or nylon strings are shown in Figure 2. The results indicated that the spray mass was going over the top of the collection structures as a baseline/zero was not observed beyond a distance of $2 \mathrm{~m}$ from the spray line. Losing mass over the top of sampler riggings is a common limitation of this type of study. For example, Khot et al. (2012b) also sampled to a height of $4.5 \mathrm{~m}$ using a portable, vertical patternator to an approximate distance of $2.0 \mathrm{~m}$ and found losses of up to $15 \%$. A normalised dye output of 0.276 $\mathrm{g} / \mathrm{s}$ in the current study and it was assumed that the spray plume would have fully developed by $2.0 \mathrm{~m}$ downwind so the exposure time would remain constant. Analysis of the collected data suggested that the best estimate of mass lost over the sampling frames ranged between $1 \%$ at $1 \mathrm{~m}$ to $40 \%$ at $5 \mathrm{~m}$ (Table 2). It is important to note that the spray plume was still under the influence of the sprayer's airstream and actively projected at all sampling distances. Therefore, droplet fallout would not be a large cause of loss.

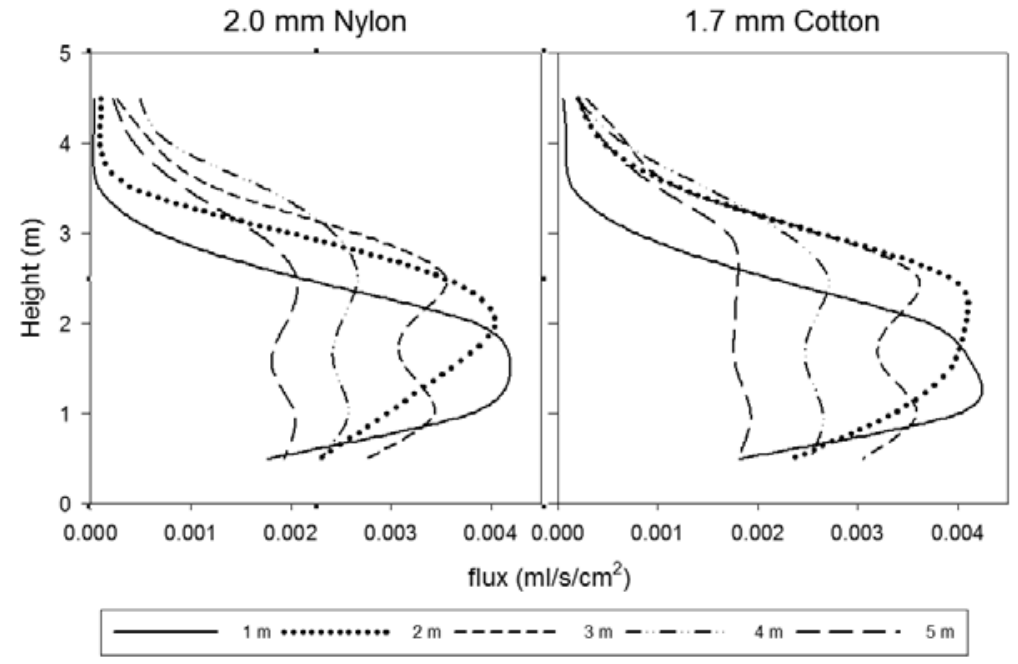

Figure 2 Flux profiles for the $2.0-\mathrm{mm}$ nylon string (left) and 1.7-mm cotton string (right) at 1, 2, 3, 4 and $5 \mathrm{~m}$ spray distances. 
Table 2 Spray deposition (g/sample) and standard deviation (SD) for pooled strings, estimated spray exposure time and spray recovery (\%).

\begin{tabular}{|c|c|c|c|c|c|}
\hline \multirow{3}{*}{ Height (m) } & \multicolumn{5}{|c|}{ Distance $(\mathrm{m})$} \\
\hline & 1 & 2 & 3 & 4 & 5 \\
\hline & \multicolumn{5}{|c|}{ Deposition \pm SD } \\
\hline 0.0 to 0.5 & $0.027 \pm 0.011$ & $0.039 \pm 0.020$ & $0.049 \pm 0.027$ & $0.039 \pm 0.022$ & $0.032 \pm 0.016$ \\
\hline$>0.5$ to 1.0 & $0.062 \pm 0.012$ & $0.055 \pm 0.025$ & $0.058 \pm 0.026$ & $0.042 \pm 0.022$ & $0.034 \pm 0.019$ \\
\hline$>1.0$ to 1.5 & $0.068 \pm 0.014$ & $0.063 \pm 0.019$ & $0.053 \pm 0.014$ & $0.040 \pm 0.019$ & $0.030 \pm 0.015$ \\
\hline$>1.5$ to 2.0 & $0.063 \pm 0.012$ & $0.069 \pm 0.015$ & $0.054 \pm 0.007$ & $0.041 \pm 0.017$ & $0.031 \pm 0.017$ \\
\hline$>2.0$ to 2.5 & $0.039 \pm 0.027$ & $0.063 \pm 0.016$ & $0.060 \pm 0.010$ & $0.044 \pm 0.014$ & $0.032 \pm 0.016$ \\
\hline$>2.5$ to 3.0 & $0.016 \pm 0.020$ & $0.043 \pm 0.031$ & $0.044 \pm 0.012$ & $0.038 \pm 0.019$ & $0.028 \pm 0.013$ \\
\hline$>3.0$ to 3.5 & $0.003 \pm 0.003$ & $0.018 \pm 0.024$ & $0.020 \pm 0.017$ & $0.026 \pm 0.018$ & $0.017 \pm 0.010$ \\
\hline$>3.5$ to 4.0 & $0.001 \pm 0.001$ & $0.007 \pm 0.010$ & $0.010 \pm 0.012$ & $0.012 \pm 0.014$ & $0.008 \pm 0.005$ \\
\hline$>4.0$ to 4.5 & $0.001 \pm 0.001$ & $0.003 \pm 0.004$ & $0.004 \pm 0.005$ & $0.006 \pm 0.012$ & $0.004 \pm 0.003$ \\
\hline Total (g) & 0.28 & 0.36 & 0.35 & 0.29 & 0.22 \\
\hline Time $(\mathrm{s})$ & 1.0 & 1.3 & 1.3 & 1.3 & 1.3 \\
\hline Recovered (\%) & 100 & 100 & 97 & 79 & 60 \\
\hline
\end{tabular}

\section{Droplet size and velocity}

An important advantage of $\mathrm{pD}$ equipment is that it can measure cumulative droplet size and velocity profiles (irrespective of sampling frequency) independently of the flux calculations. Such data cannot be obtained by strings. The measurements taken from 1 to $4 \mathrm{~m}$ included cumulative droplet profiles. The parameters Dv0.1, Dv0.5, and Dvo.9 represent the cumulative droplet volumes when the spray mass is $\leq 10 \%$, $50 \%$ and $90 \%$, respectively. The total droplet spectrum became finer at all distances from the sprayer as the spray moved upward (Table 3 ). In contrast, the droplet spectrum became coarser as the distance from the sprayer increased. Smaller droplets lose their momentum more quickly than the coarser ones, which increased the coarseness of the overall spectrum from $1 \mathrm{~m}$ to $4 \mathrm{~m}$. However, the gravitational pull on coarser droplets is greater than finer ones so larger droplets will fall out of the atmosphere and leave only those $\leq 150$ $\mu \mathrm{m}$. This class of droplets comprised $50 \%$ of the cumulative volume of nearly all measurements with this particular spray and also constituted those droplets with the greatest risk of drift.
García-Ramos et al. (2012) discussed that air velocities generated from axial fan airblast sprayers can cause discrepancies in spray deposition. They assessed a double-fanned spray system in an effort to compensate for differences in deposition caused by air pattern differences within a spray plume. The majority of orchard sprayers in New Zealand are towbehind varieties with an anti-clockwise rotation causing the air to be lifted on the right side of the sprayer and dumped on the left. This approach leads to droplet interaction and inconsistences in the vertical profile (Manktelow \& May 2011; García-Ramos et al. 2012). For example, Khot et al. (2012a) observed that flux profiles at distances of 3.0 to $4.5 \mathrm{~m}$ on the right side of the sprayer (with nozzles and air flow at $100 \%$ open) were $49 \%$ higher than on the left side. Conversely, $26 \%$ more flux was captured from 1.0 to $2.5 \mathrm{~m}$ on the left side than on the right side. The sprayer in the present study was geared in a different way to that of most sprayers. It was not directly geared through the power take-off, and so the fan rotated in a clockwise fashion, therefore a reverse affect was observed. The velocities of the droplets 
measured using the $\mathrm{pD}$ interferometer are shown in Table 4. The droplet/air velocities were quite low $(3.2$ to $3.9 \mathrm{~m} / \mathrm{s})$ at a height of $0.5 \mathrm{~m}$ from the ground but the velocity increased at higher the sampling height for all measured distances.
At a distance of $1.0 \mathrm{~m}$, a clear circular pattern was observed that corresponded to the round as it was at its closest to the $\mathrm{pD}$; by $3.0 \mathrm{~m}$ this difference plateaued.

Table 3 Cumulative sizes $(\mu \mathrm{m})$ for phase Doppler data including Dv0.1, Dv0.5, and Dv0.9. Data with different letters in the same column are significantly different $(\mathrm{P}<0.05)$.

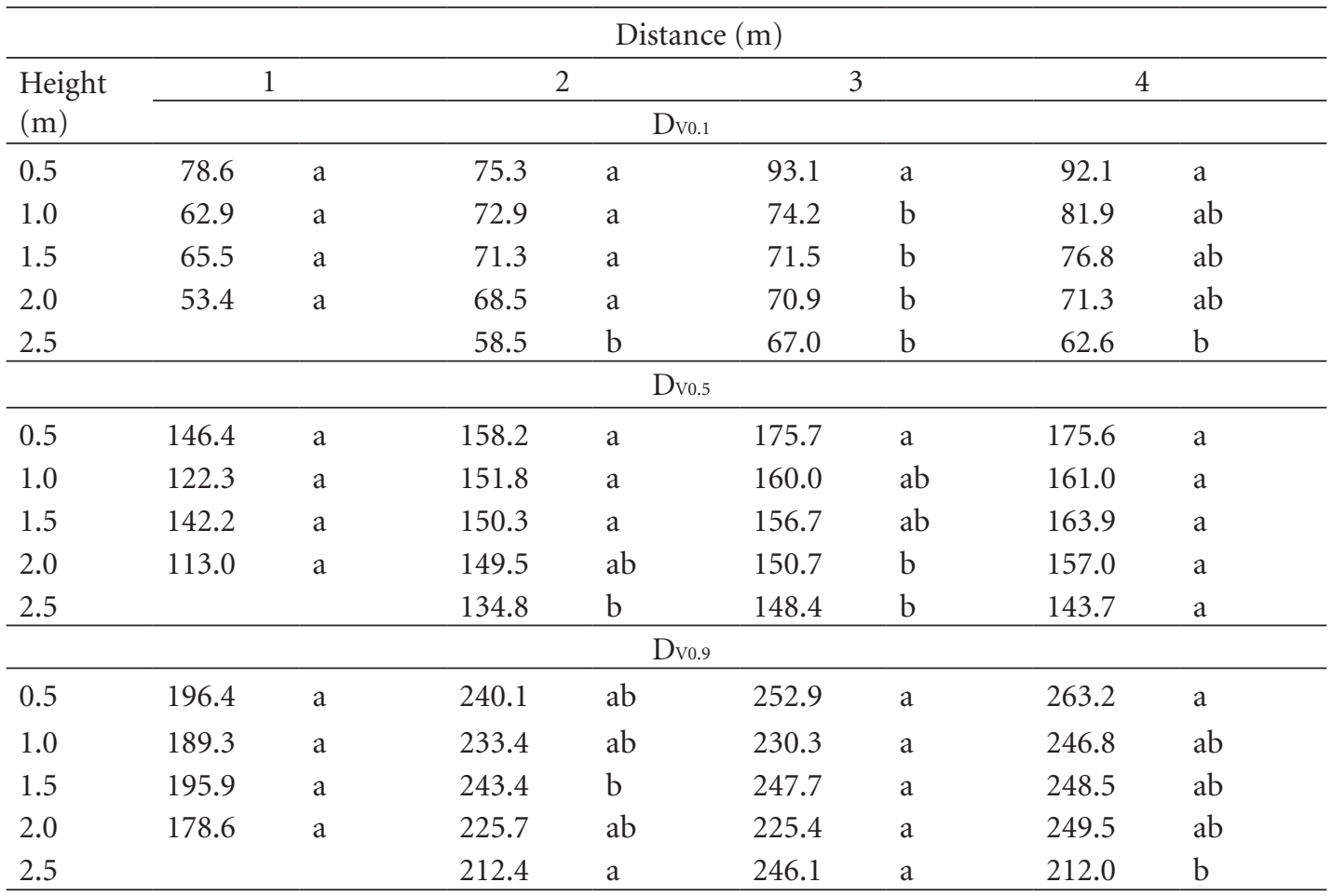

Table 4 Mean phase Doppler velocity $(\mathrm{m} / \mathrm{s})$ data per height and distance. Data with different letters in the same column are significantly different $(\mathrm{P}<0.05)$.

\begin{tabular}{|c|c|c|c|c|c|c|c|c|}
\hline \multicolumn{9}{|c|}{ Distance $(\mathrm{m})$} \\
\hline \multirow{2}{*}{$\begin{array}{l}\text { Height } \\
(\mathrm{m})\end{array}$} & \multicolumn{2}{|c|}{1} & \multicolumn{2}{|c|}{2} & \multicolumn{2}{|c|}{3} & \multicolumn{2}{|c|}{4} \\
\hline & \multicolumn{8}{|c|}{ Velocity (m/s) } \\
\hline 0.5 & 3.7 & a & 3.9 & $\mathrm{a}$ & 3.2 & a & 3.5 & $\mathrm{a}$ \\
\hline 1.0 & 15.5 & $\mathrm{~b}$ & 7.2 & $\mathrm{~b}$ & 4.5 & $\mathrm{~b}$ & 4.1 & $\mathrm{~b}$ \\
\hline 1.5 & 12.1 & c & 7.2 & $\mathrm{~b}$ & 5.9 & c & 5.0 & bc \\
\hline 2.0 & 13.1 & c & 7.7 & $\mathrm{~b}$ & 6.3 & $\mathrm{~d}$ & 5.2 & bc \\
\hline 2.5 & & & 8.0 & $\mathrm{~b}$ & 7.4 & d & 6.7 & c \\
\hline
\end{tabular}


The differences observed in droplet size and velocity produced by the sprayer are important with respect to understanding the fate of plant-protection chemicals. Nozzle selection, configuration and orientation are critical factors to achieve adequate coverage and mitigate spray drift when calibrating these sprayers (Manktelow \& May 2011). Studies using fundamental spray data have shown that smaller droplet spectrums provide better coverage but that air assistance is required to carry the droplets upwards as well as to penetrate the canopy (Tuck et al. 1997; Fox et al. 2008). However, these two parameters are also responsible for spray drift. Conversely, larger droplets such as those produced by air-induction nozzles, hold their momentum for longer (Tuck et al. 1997). Large droplets provide good coverage in easy-to-reach locations and minimise drift but they are more likely to bounce, shatter and fall off-target (Spillman 1984; Schou et al. 2012).

Consideration of spray characteristics and canopy retention are important factors to consider when choosing a suitable sampling method so that spray mass is collected. String samplers composed of cotton, wool or synthetic yarn have been used in various mass balance and drift experiments because they are considered to have nearly $100 \%$ collection efficiencies. These high collection efficiencies have been attributed to the yarn's ability to absorb as well as the presence of omnidirectional fine hairs, which can collect fine droplets within the plume (Cooper et al. 1996; Roten 2016a). Such absorbency does provide some benefit over smooth string samplers in low flux environments (i.e. drift). However, no notable dissimilarities were apparent for either smooth nylon or cotton strings when exposed to the high flux conditions tested here. Further, Forster et al. (2014) explained the need for artificial collectors that will not only capture and retain spray mass, but also determine the spray volume and droplet size. All these criteria are important for discerning collection efficiencies and strings alone cannot achieve this (Fox et al. 2008).

In conclusion, the $\mathrm{pD}$ technology alone did not perform as expected but a combination of strings and $\mathrm{pD}$ equipment can be quite useful by providing additional information on droplet velocity and size relative to sprayer location. This study showed that $\mathrm{pD}$ technology is not yet ready to replace string samplers, however, it could certainly be a useful tool in the future to better understand the production and fate of sprayed droplets.

\section{ACKNOWLEDGEMENTS}

The authors would like to extend our gratitude to the Lincoln University Field Service Centre and the Biological Husbandry Unit (BHU) for their assistance with equipment and field site. Also thanks to Travis Cook and Kevin Wang for their laboratory contributions.

\section{REFERENCES}

Anon. 2015. FreshFacts. http://www.freshfacts. co.nz/files/freshfacts-2015.pdf (accessed 1 March 2017).

Bachalo WD 1980. Method for measuring the size and velocity of spheres by dual-beam light-scatter interferometry. Applied Optics 19: 363-370.

Bachalo WD, Houser MJ 1984. Phase/ Doppler spray analyzer for simultaneous measurements of drop size and velocity distributions. Optical Engineering 23: 235583-235583-.

Balsari P, Marucco P, Tamagnone M 2005. Technical Note: A system to assess the mass balance of spray applied to tree crops. Transactions of the ASAE, 48: 1689-1694.

Bui QD, Womac AR, Howard KD, Mulrooney JE, Amin MK 1998. Evaluation of samplers for spray drift. Transactions of the ASAE, 41(1): 37-41.

Chuang PY, Saw EW, Small JD, Shaw RA, Sipperley CM, Payne GA, Bachalo WD 2008. Airborne phase doppler interferometry for cloud microphysical measurements. Aerosol Science and Technology 42: 685-703.

Cooper JF, Smith DN, Dobson HM 1996. An evaluation of two field samplers for monitoring spray drift. Crop Protection 15: 249-257. 
Dullenkopf K, Willmann M, Wittig S, Schöne F, Stieglmeier M, Tropea C, Mundo C 1998. Comparative mass flux measurements in sprays using a patternator and the phasedoppler technique. Particle \& Particle Systems Characterization 15: 81-89.

Forster WA, Gaskin RE, Strand TM, Manktelow DWL, van Leeuwen RM 2014. Effect of target wettability on spray droplet adhesion, retention, spreading and coverage: artificial collectors versus plant surfaces. New Zealand Plant Protection 67: 284-291.

Fox RD, Brazee RD, Reichard DL, Hall FR 1990. Downwind residue from air spraying of a dwarf apple orchard. Transactions of the ASAE 33(4) 1104-1108.

Fox RD, Derksen R, Cooper J, Krause C, Ozkan H 2003. Visual and image system measurement of spray deposits using water-sensitive paper. Applied Engineering in Agriculture 19: 549-554.

Fox RD, Derksen RC, Zhu H, Brazee RD, Svensson SA 2008. A History of air-blast sprayer development and future pospects. Transactions of the ASAE, 51(2) 405.

García-Ramos FJ, Vidal M, Boné A, Malón H, Aguirre J 2012. Analysis of the air flow generated by an air-assisted sprayer equipped with two axial fans using a 3D sonic anemometer. Sensors (Basel, Switzerland) 12: 7598-7613.

Hewitt AJ, Roten RL, Giles DK, Bachalo W, Connell R 2013. A new phase Doppler interferometer system for evaluation of pesticide sprays in the field. In: ILASS Americas, 25th Annual Conference of Liquid Atomization and Spray systems, Pittsburgh, PA, USA. May 2013.

Khot LR, Ehsani R, Albrigo G, Landers AJ, Larbi PA 2012a. Technical Note: Spray pattern investigation of an axial-fan Airblast precision sprayer using a modified vertical patternator. Applied Engineering in Agriculture 28(5): 647-654.

Khot LR, Ehsani R, Albrigo G, Larbi PA, Landers A, Campoy J, Wellington C 2012b. Air-assisted sprayer adapted for precision horticulture:
Spray patterns and deposition assessments in small-sized citrus canopies. Biosystems Engineering 113: 76-85.

Lo PL, Walker JTS 2016. Occurrence of oriental fruit moth (Grapholita molesta) in apple orchards in New Zealand. New Zealand Plant Protection 69: 133-137.

Manktelow DW, May B 2011. Spray nozzle guide. http://www.kvh.org.nz/vdb/document/896 (accessed on 4 April 2017).

Manktelow DW, Stevens P, Walker J, Gurnsey S, Park N, Zabkiwicz J, Teulon D, Rahman A 2005. Trends in pesticide use in New Zealand: 2004. http://www.dioxinnz.com/Spray-NZHist/PDF/nz-pesticide-trends.pdf (accessed 1 April 2017)

Miller D, Stoughton T, Steinke W, Huddleston E, Ross J 2000. Atmospheric stability effects on pesticide drift from an irrigated orchard. Transactions of the ASAE 43: 1057-1066.

Roten RL, Connell RJ, Hewitt AJ, Woodward SJR 2015a. Comparison of spray dose measured on leaf surfaces with spray coverage estimated from Kromekote ${ }^{\circledR}$ paper. New Zealand Plant Protection 68: 38-43.

Roten RL, Ferguson JC, Connell RJ, Gary JD, Hewitt AJ 2015b. Preliminary investigation of Phase Doppler derived flux measurements in a wind tunnel for the sampling of orchard spray drift. Proceedings of the 13th Workshop on Spray Application in Fruit Growing: 43-44.

Roten RL, Post SL, Hewitt AJ 2016a. Phase doppler flux comparisons. In: 2016 ASABE Annual International Meeting. 162461508. St. Joseph, MI., USA. P. 1.

Roten RL, Post SL, Werner A, Hewitt AJ, Safa M 2016b. Volumetric validation of mass balance using a computational phase Doppler approach for disc core nozzles. Crop Protection 79: 128-134.

Rudoff RC, Bachalo EJ, Bachalo WD 1992. Performance of the phase Doppler particle analyzer in the NASA Lewis Icing Research Tunnel. In the Proceedings of the 30th Aerospace Sciences Meeting and Exhibit, Reno, NV, USA Jan. 6-9. 
Salyani M, Farooq M, Sweeb RD 2007. Spray deposition and mass balance in citrus orchard applications. Transaction of the ASABE 50(6): 1963-1969.

Schou WC, Forster WA, Mercer GN, Teske ME, Thistle HW 2012. Building canopy retention into AGDISP: preliminary models and results. Transaction of the ASABE 55(6): 2059-2066.

Spillman JJ 1984. Spray impaction, retention and adhesion: An introduction to basic characteristics. Pesticide Science 15: 97-106.
Tuck CR, Ellis MCB, Miller PCH 1997. Techniques for measurement of droplet size and velocity distributions in agricultural sprays. Crop Protection 16: 619-628.

Vanneste JL, Yu J, Cornish DA, Max S, Clark G 2011. Presence of Pseudomonas syringae pv. actinidiae, the causal agent of bacterial canker of kiwifruit, on symptomatic and asymptomatic tissues of kiwifruit. New Zealand Plant Protection 64: 241-245.

Whitney RW, Roth LO 1985. String collectors for spray pattern analysis. Transactions of the ASAE 28(6): 1749-1753. 